\title{
A cadaveric study of coronary arteriesin Rayalaseema population of Andhra Pradesh
}

\author{
J. Vasudeva Reddy ${ }^{1, *}$, C. Sreekanth ${ }^{2}$, S. Lokanadham ${ }^{3}$ \\ ${ }^{1}$ Professor, ${ }^{2}$ Associate Professor, Dept. of Anatomy, Sri Padmavathi Medical College, Tirupathi, Andhra Pradesh, \\ ${ }^{3}$ Assistant Professor, Dept. of Anatomy, Shantiram Medical College, Andhra Pradesh, India \\ *Corresponding Author: J. Vasudeva Reddy \\ Email: sln.uoh10@gmail.com
}

Received: $20^{\text {th }}$ December, 2016

Accepted: $4^{\text {th }}$ August, 2018

\begin{abstract}
Introduction: Majority of the sudden cardiac deaths were due to anomalous origin and distribution of the coronary arteries. Aim: To study the arterial vascular pattern of the human heart by using dissection method in Rayalaseema population.

Materials and Methods: A total of 80 human fresh heart specimens were obtained from the Department of Forensic Medicine, S.V. Medical College, Tirupati for the present study.

Results: We have observed both the coronary arteries arising from single coronary ostia in 76 specimens whereas 4 heart specimens noted with coronary arteries originated from two ostia. Right and left dominance circulation was noted more in males than females. We have also observed double posterior interventricular branches arising from the right and left coronary arteries showing the balanced type of coronary circulation in 2 (Male-1; Female-1) hearts.

Conclusion: Arterial pattern and its variations are important to prevent false interpretation of the arterial angiograms in management of coronary artery diseases.
\end{abstract}

Keywords: Arteries, Branches, Coronary, Dominance.

\section{Introduction}

The right and left coronary arteries arise from the ascending aorta in its anterior and left posterior sinuses. The levels of the coronary ostia are variable. The main arteries and major branches are usually subepicardial, but those in atrioventricular and interventricular groove are often deeply sited. ${ }^{1}$ It has been reported that the posterior inter ventricular branch branches off from the RCA in $75 \%$ of cases (right dominance) and from the LCA in $10 \%$ of cases (left dominance), and goes around the back of the anterior inter ventricular branch, creating an anastomosis with the posterior inter ventricular branch in $15 \%$ of cases as balanced circulation in humans. ${ }^{2}$ Atherosclerotic involvement of the Right coronary artery and the Left circumflex artery is more common in right dominant heart. ${ }^{3}$ Left dominance is a significant and independent predictor of increased long-term mortality in acute coronary syndrome. ${ }^{4,5}$ The present study was undertaken to study the arterial pattern of the coronary arteries and their branches in cadavers which helps in understanding the coronary artery diseases.

\section{Materials and Methods}

Human fresh hearts $(n=80)$ with a portion of ascending aorta were collected from the Department of Forensic Medicine, S.V. Medical College, Tirupati. All the heart specimens were cleaned from free of clots and the branches of coronary arteries were dissected from the coronary ostia to as distal as possible in the present study. The branches of both the coronary arteries and their variations were noted and photographed. The ethical committee clearance was taken from the S.V. Medical College Ethical Committee, Tirupathi for the present study.

\section{Results}

The origin of both the coronary arteries arising from single ostia was observed in 76 specimens whereas coronary arteries arising from two coronary ostia were noted in 4 specimens in the present study. The right conus artery, sinoatrial nodal branch, right marginal artery, posterior interventricular branch and atrial and ventricular rami of the right coronary arteries were observed (Fig. 1). The branches of left coronary arteries like left anterior descending, left circumflex, diagonal, left marginal branches were also noted in the present study (Fig. 2). We have observed right and left dominance and balanced type of circulation (Table 1). The origin of posterior interventricular artery and branch to atrioventricular node are the factors for dominance pattern. We have observed the posterior interventricular artery and AV nodal branches are arising from the left circumflex branch of left coronary artery showing left coronary dominance in 9 specimens (Fig. 3). Right and left dominance circulation was noted more in males than females. We have observed double posterior interventricular branches arising from the right and left coronary arteries showing the balanced type of coronary circulation in 2 (Male-1; Female-1) hearts (Fig. 4). The septal perforators, left anterior descending branches of left coronary arteries were also noted (Fig. 5). 
Table 1: Comparison of coronary arterial pattern of various authors with the present study

\begin{tabular}{|c|c|c|c|c|c|c|c|}
\hline \multirow[t]{2}{*}{ Name of the Authors } & \multirow[t]{2}{*}{$\begin{array}{c}\text { No. } \\
\text { Specimens }\end{array}$} & \multicolumn{2}{|c|}{$\begin{array}{l}\text { Right coronary } \\
\text { dominance }\end{array}$} & \multicolumn{2}{|c|}{$\begin{array}{c}\text { Left coronary } \\
\text { dominance }\end{array}$} & \multicolumn{2}{|c|}{$\begin{array}{c}\text { Balanced } \\
\text { circulation }\end{array}$} \\
\hline & & No. & $\%$ & No. & $\%$ & No. & $\%$ \\
\hline Schlesinger (1940) & 225 & 108 & 48 & 41 & 18 & 76 & 34 \\
\hline Ayer \&Rao (1957) & 35 & 11 & 44 & 7 & 28 & 7 & 28 \\
\hline Jain \&Hazary (1958) & 30 & 17 & 56.6 & 3 & 10 & 10 & 33.4 \\
\hline Kalpana (2003) & - & - & 89 & - & 11 & - & - \\
\hline Das (2010) & - & - & 70 & - & 18.5 & & 11.5 \\
\hline Bezbaruah (2003) & - & - & 76 & - & 20 & - & 4 \\
\hline Present study & 80 & $\begin{array}{c}69 \\
(m-48, f-21)\end{array}$ & 86.5 & $\begin{array}{c}9 \\
(\mathrm{~m}-8, \mathrm{f}-1)\end{array}$ & 11 & $\begin{array}{c}2 \\
(\mathrm{~m}-1, \mathrm{f}-1)\end{array}$ & 2.5 \\
\hline
\end{tabular}

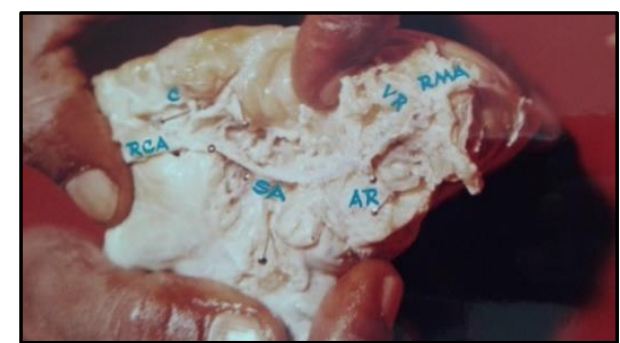

Fig. 1: Dissected heart specimen showing branches of right coronary artery (RCA: Right coronary artery; C: conus artery; SA: sino atrial nodal branch; AR: atrial rami; VR: ventricular rami; RMA: right marginal arteries

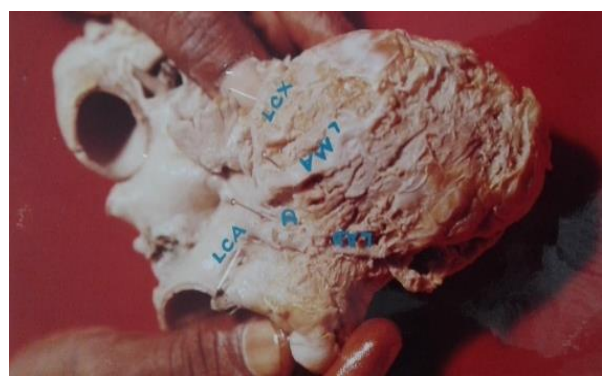

Fig. 2: Dissected heart specimen showing branches of left coronary artery (LCA: Left coronary artery; LAD: Left anterior descending; D: Diagonal; LMA: Left marginal; LCX: Left circumflex arteries

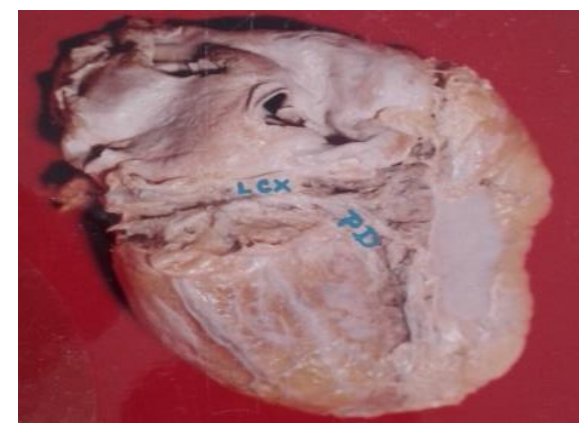

Fig. 3: Heart specimen showing posterior interventricular artery from left circumflex artery (LCX: left circumflex; PD: posterior interventricular artery)

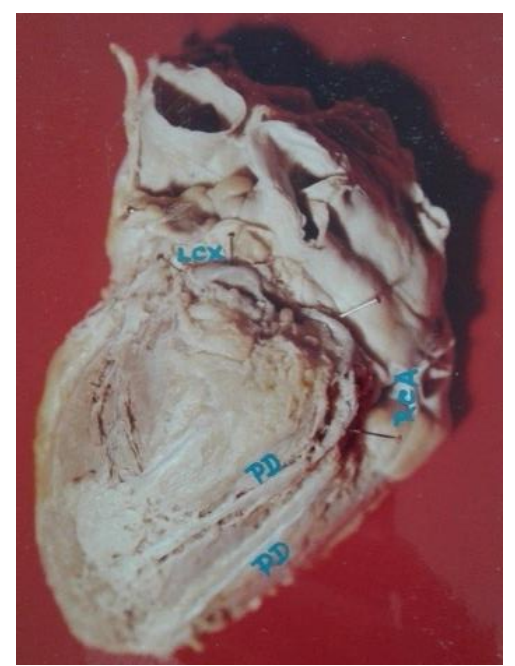

Fig. 4: Heart specimen showing posterior interventricular branches arising from right and left coronary arteries (LCX: left circumflex; PD: posterior interventricular artery; RCA: Right coronary artery

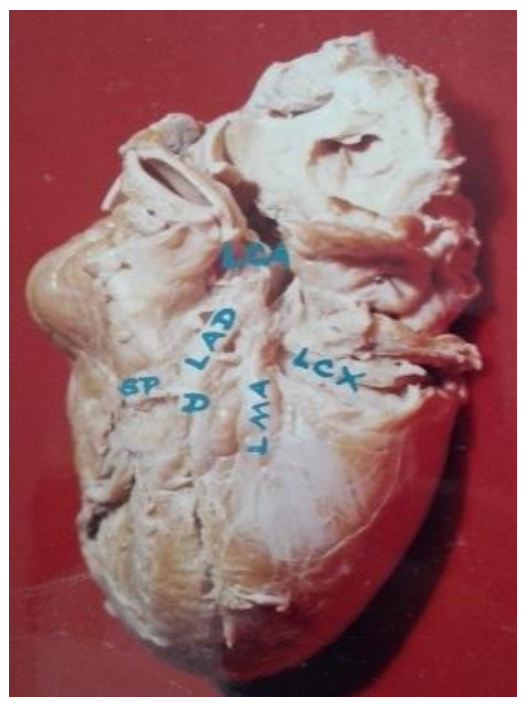

Fig. 5: Dissected heart specimen showing the left coronary artery branches (LCA: left coronary artery; LMA: Left marginal artery; LAD: left anterior descending; D: diagonal; LCX: left circumflex; SP: septal perforators) 


\section{Discussion}

We have observed right coronary artery originating from the two coronary ostia in 4 heart specimens in the present study. The extra ostium may be due to conus branch arising directly from aorta is observed in $50 \%$ of cases. ${ }^{6}$ Left coronary sinus with absence of multiple ostia leads to myocardial perfusion by various branches of left coronary artery are more likely to suffer infarction than right coronary artery. ${ }^{7}$ Coronary predominance was higher in males than females in the present study indicating the reason for higher incidence of myocardial infarction in males than females. Right predominance was higher in males when compared to females in the present study. Dominance plays an important role in inferior infarcts of the heart. The dominant RCA usually supplies the atrio-ventricular $(\mathrm{AV})$ node. An inferior wall infarct caused by occlusion of the RCA will have higher risk of AV block. ${ }^{8,9}$ Dominance pattern of heart has an important clinical significance on coronary blood flow volume in the left circumflex and right coronary arteries suggests that the extent of myocardial perfusion area is associated with coronary blood flow volume. ${ }^{10}$ Murphy et al has noted in their study that patients with left dominance have a shorter left main coronary artery than patients with right dominance. ${ }^{11}$ The coronary ostia, dominance, anastomotic branches of coronary arteries in the present study are in agreement with previous literature which gives basic knowledge to the clinicians. ${ }^{9,12,13}$

\section{Conclusion}

The knowledge of human heart arterial pattern and its variations are important to understand the arterial angiograms in management of coronary artery diseases.

\section{Conflict Interest: Nil}

\section{Acknowledgements}

Authors are thankful to Prof. Dr. R.V. Subhakar for his valuable guidance and advice during this work.

\section{References}

1. Williams P, Bannister LH, Berry MM, Collins P, Dyson M, Dussek JE. (1995) cardiovascular system- The arterial system. Glabella G, editor. Gray's Anatomy. The Anatomical Basis of Medicine and Surgery. 38th ed. Edinburgh, London: Churchill Livingstone;1505-10.

2. Snell RS. (1981) Clinical Anatomy. $5^{\text {th }}$ edition; Boston (MA): Little Brown and Company Inc. p. 97-98.

3. Vasheghani- Farahani A, Kassaian SE, Yaminisharif A, Davoodi G, Salarifar M. The association between coronary arterial dominancy and extent of CAD in angioplasty and paraclinical studies. Clin Anat. 2008;519523.

4. Goldberg A., Southern D. Galbraith P.D., Traboulise M., Knudtson ML, Ghali WA. Coronary dominance and prognosis of patient with acute coronary syndrome. Am Heart J. 2007;154(6):1116-22.

5. James TN. Anatomy of the coronary arteries. New York. Paul B Hoeber. 1961;12-150.
6. L. Beach, A. Burke, D. Chute, and R. Virmani Anomalous origin of 4 coronary ostia from the right sinus of valsalva in a patient with hypertrophic cardiomyopathy. Archives of Pathology and Laboratory Medicine. 2001;125(11):1489-1490.

7. Baroldi Mantero and Scomazzoni. The collaterals of the coronary arteries in normal and pathological heart. Circulation Research. 1976;4:223.

8. Schlesinger MJ. Relation of anatomic pattern to pathological conditions of the coronary arteries. Arch Path. 1940;30:403-415.

9. Bezbaruah NK. (2003) An anatomical study of human coronary arteries in North Eastern population. Degree of Master of Surgery (Anatomy) [thesis]. Dibrugarh University.

10. Sakamoto, Takahashi S, Coskun AU, Papafaklis MI, Takahashi A, Saito S. Relation of distribution of coronary blood flow volume to coronary artery dominance. American Journal of cardiology. 2013;111(10):1420-4.

11. Murphy ES, Rösch J, Rahimtoola SH. Frequency and significance of coronary arterial dominance in isolated aortic stenosis. J Cardiol. 1977;39(4):505-9.

12. Das H, Das G, Chandradas D, Talukdar K. A Study of Coronary Dominance in the population of Assam. Journal of Anatomical Society of India. 2010;59(2):187191.

13. Kalpana R. A Study on Principal Branches of Coronary Arteries in Humans. Journal of Anatomical Society of India. 2003;52(2):137-140.

How to cite this article: Reddy J. V, Sreekanth C, Lokanadham S. A cadaveric study of coronary arteriesin Rayalaseema population of Andhra Pradesh. Indian J Clin Anat Physiol. 2018;5(4):454-456. 